\title{
Manumycin A induces apoptosis in malignant pleural mesothelioma through regulation of Sp1 and activation of the mitochondria-related apoptotic pathway
}

\author{
KA HWI KIM $^{1 *}$, JUNG-IL CHAE ${ }^{2 *}$, HANA OH $^{1}$, JIN HYOUNG CHO ${ }^{2}$, RA-HAM LEE ${ }^{2}$, GOO YOON $^{1}$, \\ SEUNG-SIK CHO ${ }^{1}$, YOUNG-SIK $\mathrm{CHO}^{3}$, MEE-HYUN LEE ${ }^{4}$, KANGDONG LIU ${ }^{4,5}$, \\ HYUN-JEONG LEE ${ }^{6}$ and JUNG-HYUN SHIM ${ }^{1}$
}

\begin{abstract}
${ }^{1}$ Department of Pharmacy, College of Pharmacy and Natural Medicine Research Institute, Mokpo National University, Jeonnam 534-729; ${ }^{2}$ Department of Dental Pharmacology, School of Dentistry and Institute of Oral Bioscience, BK21 Plus, Chonbuk National University, Jeonju 651-756; ${ }^{3}$ College of Pharmacy, Keimyung University, Dalseo-gu, Daegu 704-701, Republic of Korea; ${ }^{4}$ The China-US (Henan) Hormel Cancer Institute, Zhengzhou, Henan 450001;

${ }^{5}$ School of Basic Medical Sciences, Zhengzhou University, Zhengzhou, Henan 450001, P.R. China;

${ }^{6}$ Division of Animal Genomics and Bioinformatics, National Institute of Animal Science,

Rural Development Administration, Suwon 441-706, Republic of Korea
\end{abstract}

Received February 29, 2016; Accepted April 11, 2016

DOI: 10.3892/or.2016.4801

\begin{abstract}
Manumycin A (Manu A) is a natural product isolated from Streptomyces parvulus and has been reported to have anti-carcinogenic and anti-biotic properties. However, neither its molecular mechanism nor its molecular targets are well understood. Thus, the aim of the present study was to explore the possibility that Manu A has cancer preventive and chemotherapeutic effects on malignant pleural mesothelioma
\end{abstract}

Correspondence to: Professor Jung-Hyun Shim, Department of Pharmacy, College of Pharmacy, Mokpo National University, 1666 Youngsan-ro, Muan-gun, Jeonnam 534-729, Republic of Korea E-mail: s1004jh@gmail.com

Dr Hyun-Jeong Lee, Division of Animal Genomics and Bioinformatics, National Institute of Animal Science, Rural Development Administration, 564 Omockchun-dong, Suwon 441-706, Republic of Korea

E-mail: hyunj68@korea.kr

*Contributed equally

Abbreviations: MPM, malignant pleural mesothelioma; Manu A, Manumycin A; Sp1, specificity protein 1; RPMI-1640, Roswell Park Memorial Institute-1640 medium; Mcl-1, myeloid cell leukemia-1, PARP, poly(ADP-ribose) polymerase; MTS, 3-(4,5-dimethylthiazol2-yl)-5-(3-carboxymethoxy phenyl)-2-(4-sulfophenyl)-2Htetrazolium; DAPI, 4'-6-diamidino-2-phenylindole; RT, room temperature; 7-AAD, 7-aminoactinomycin D; MMP, mitochondrial membrane potential

Key words: Manumycin A, apoptosis, specificity protein 1, malignant pleural mesothelioma
(MPM) through regulation of Sp1 and induction of mitochondrial cell death pathway. Manu A inhibited the cell viability of MSTO-211H and $\mathrm{H} 28$ cells in a concentration-dependent manner as determined by MTS assay. $\mathrm{IC}_{50}$ values were calculated as 8.3 and $4.3 \mu \mathrm{M}$ in the MSTO-311H and $\mathrm{H} 28$ cells following $48 \mathrm{~h}$ incubation, respectively. Manu A induced a significant increase in apoptotic indices as shown by DAPI staining, Annexin V assay, multi-caspase activity and mitochondrial membrane potential assay. The downregulation of Sp1 mRNA and protein expression by Manu A led to apoptosis by suppressing Sp1-regulated proteins (cyclin D1, Mcl-1 and survivin). Manu A decreased the protein levels of BID, Bcl-xL and PARP while it increased Bax levels. Manu A caused depolarization of the mitochondrial membrane with induction of CHOP, DR4 and DR5. Our results demonstrated that Manu A exerted anticancer effects by inducing apoptosis via inhibition of the Sp1-related signaling pathway in human MPM.

\section{Introduction}

Malignant pleural mesothelioma (MPM) is the most common and aggressive primary tumor of the pleura $(1,2)$. It is a rare asbestos-related neoplasm of the serosal membrane (3). It is extremely difficult to treat, being invariably fatal (4). MPM is attributed to the widespread use of asbestos as an insulator over the latter half of the last century (5-7). Other potential carcinogenic factors are exposure to simian virus 40 and radiation $(8,9)$. Median survival time for untreated MPM patients ranges from 4 to 12 months $(10,11)$. Moreover, its mortality rates are estimated to increase by $5-10 \%$ per year in most industrialized countries until $2020(1,12)$.

Specificity protein $1(\mathrm{Sp} 1)$ is the founding member of a family of zinc finger transcription factors, which play important 
physiological roles such as cell cycle regulation, cell proliferation and cell apoptosis (13-15). As compared with normal tissues or cells, Sp1 levels are high in many types of cancer cells, such as breast carcinomas, thyroid cancer, hepatocellular carcinomas, pancreatic cancer, colorectal cancer, gastric cancer and lung cancer (13). For these reasons, downregulation of $\mathrm{Sp} 1$ is regarded as a potential strategy for treating MPM.

Manumycin A (Manu A) is a natural product from Streptomyces parvulus and acts as a potent and selective Ras farnesyltransferase inhibitor (16,17). Farnesyl protein transferase is important in activating a variety of signaling proteins including Ras $(17,18)$. Recently, the anti-neoplastic activity of Manu A has been demonstrated in various experimental systems (18). It exerts antitumor activity against a variety of cancer cells such as human pancreatic cancer cells (19), anaplastic thyroid cancer cells $(20,21)$, human colon tumor cells (22) and human hepatocellular carcinoma HepG2 cells (23), medulloblastoma cells (24,25), leukemic cells (26), lymphoid tumor and myeloma cell lines $(27,28)$. However, little is known concerning the anticancer mechanisms of Manu A by which it can induce apoptosis in MPM cells.

Apoptosis is a physiological process that causes selective cell loss, and is an essential regulatory event to maintain the homeostasis of tissues (29-31). It can be triggered by various extracellular and intracellular stimuli via either an extrinsic or intrinsic pathway depending on cell type (31). The extrinsic pathway is initiated by cell surface receptors, while the intrinsic pathway is activated by releasing cytochrome $c$ into the cytoplasm by loss of mitochondial membrane potential and activating cascade $(30,31)$.

The aims of the present study were to investigate the death mode and the engagement of the mitochondrial-mediated pathway when MPM cells are exposed to Manu A. Based on the reports that Manu A has antitumor activity against many cancer cell lines, we investigated whether Manu A might have anticancer activity in MPM through downregulation of Sp1 and induction of mitochondrial cell death pathways.

\section{Materials and methods}

Purification of manumycin from Streptomyces sp. All the solvents used in the experiments were of extra-pure grade. Hexane, ethyl acetate and acetonitrile were purchased from J.T. Baker (Phillipsburg, NJ, USA). Silica gel for thin layer chromatography and precoated silica gel plate (Kieselgel 60F254; Merck, NJ, USA) was used. Silica gel for silica gel column, Kieselgel 60 (70-230 mesh; Merck), was used to purify manumycin. CS392 was grown on a rotary shaker at $180 \mathrm{rpm}$ in Emerson media for $2-3$ days at $28^{\circ} \mathrm{C}$. Culture broth (3L) was centrifuged at $6,000 \mathrm{rpm}$ for $20 \mathrm{~min}$. The supernatant was extracted two times with ethyl acetate $(1: 1$, $\mathrm{v} / \mathrm{v})$. The extracted ethyl acetate fraction was evaporated and dried using a rotary evaporator at $50^{\circ} \mathrm{C}$ under reduced pressure. Purification of the antibiotic was carried out by silica gel column chromatography $(0.8 \times 15 \mathrm{~cm})$. After washing the column with hexane, active material was eluted from the column with hexane-ethyl acetate (4:1). Active fractions were collected and rechromatographed, using a reverse phase-C18 silica gel column $(1.0 \times 15 \mathrm{~cm})$ with $0.01 \%$ formic acid-acetonitrile (4:6) to isolate manumycin.
Cell culture. The human MPM MSTO-211H and H28 cells were purchased from the American Tissue Culture Collection (ATCC; Manassas, VA, USA). The MSTO-211H and H28 cells were grown in RPMI-1640 medium, supplemented with $10 \%$ fetal bovine serum, $2 \mathrm{mM}$ L-glutamine and $100 \mathrm{U} / \mathrm{ml}$ each of penicillin and streptomycin (Thermo Scientific, Logan, UT, USA) at $37^{\circ} \mathrm{C}$ in a humidified atmosphere of $5 \% \mathrm{CO}_{2}$ and $95 \%$ air.

MTS assay. Cell viability was determined using the 3-(4,5-dimethylthiazol-2-yl)-5-(3-carboxymethoxyphenyl)-2(4-sulphophenyl)-2H-tetrazolium (MTS) dye-reduction assay. MSTO-211H $\left(3 \times 10^{3}\right)$ and $\mathrm{H} 28\left(2 \times 10^{3}\right)$ cells were seeded into 96-well plates for 24 and $48 \mathrm{~h}$ treated with various concentrations $(2.5,5$ and $10 \mu \mathrm{M})$ of Manu A. The cells were incubated with MTS solution for $2 \mathrm{~h}$. Absorbance was determined using an EnSpire Multimode plate reader (Perkin-Elmer, Waltham, MA, USA) at $490 \mathrm{~nm}$. Experiments were carried out in triplicates on different days. The percentage of viability was calculated as: Viable cells $(\%)=($ Manu A-treated cell to measure the absorbance - Manu A-treated blank wells (no cells) to measure the background absorbance)/absorbance of the untreated sample x 100 .

4',6-diamidino-2-phenylindole (DAPI) staining. MSTO-211H and $\mathrm{H} 28$ cells treated with Manu A were harvested by trypsin and fixed in $100 \%$ methanol at room temperature (RT) for $2 \mathrm{~h}$. The cells were spread on slides, stained with DAPI solution $(2 \mu \mathrm{g} / \mathrm{ml})$ and analyzed under a FluoView confocal laser microscope (Fluoview FV10i; Olympus Corporation, Tokyo, Japan).

Annexin $V$ staining. The cells were seeded on 6-well plates for MSTO-211H, H28 and treated with various concentrations of Manu A for $48 \mathrm{~h}(2.5,5$ and $10 \mu \mathrm{M})$. The cells were harvested by trypsinization and were incubated with Annexin V/7-aminoactinomycin (7-AAD) for $20 \mathrm{~min}$ at RT in the dark for detection of apoptosis. Apoptotic and necrotic cells were analyzed by Muse Cell analyzer (Merck Millipore, Billerica, MA, USA) using the Muse Annexin V \& Dead Cell kit (MCH100105; Merck Millipore). The experiment was performed in triplicate independently.

$R T$-PCR. Total RNA was extracted from the cells using TRIzol ${ }^{\circledR}$ reagent (Life Technologies, Carlsbad, CA, USA), and $2.5 \mu \mathrm{g}$ of RNA was used to synthesize cDNA using the HelixCript ${ }^{\mathrm{TM}}$ First Strand cDNA Synthesis kit (NanoHelix, Korea). Amplimers were obtained by PCR using $\beta$-actin-specific and Sp1-specific primers as described below under following PCR conditions $\left(25\right.$ cycles: $1 \mathrm{~min}$ at $95^{\circ} \mathrm{C}, 1 \mathrm{~min}$ at $56^{\circ} \mathrm{C}$, and $1 \mathrm{~min}$ at $72^{\circ} \mathrm{C}$ ). The $\beta$-actin primers used were; forward, $5^{\prime}-\mathrm{GTG}$ GGG CGC CCC AGG CAC CA-3' and reverse, 5'-CTC CTT AAT GTC ACG CAC GAT TTC-3'; and the Sp1 primers were; forward, 5'-ATG CCT AAT ATT CAG TAT CAA GTA-3' and reverse, 5'-CCC TGA GGT GAC AGG CTG TGA-3'. PCR products were analyzed by $2 \%$ agarose gel electrophoresis.

Western blotting. Western blot analyses were performed using cell lysates. Lysates of the treated cells were prepared using PRO-PREP ${ }^{\mathrm{TM}}$ protein extraction solution (iNtRON Biotechnology, Korea), followed by centrifugation and 
A

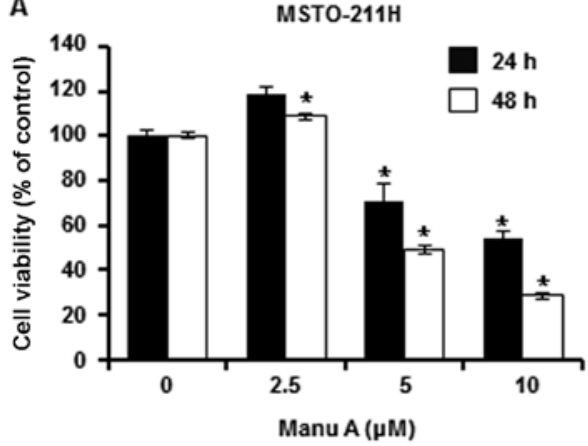

C

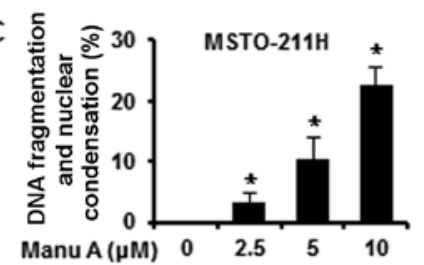

MSTO-211H

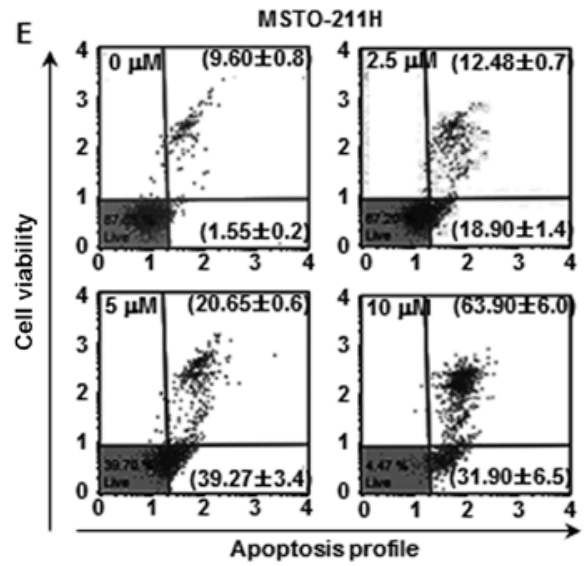

B

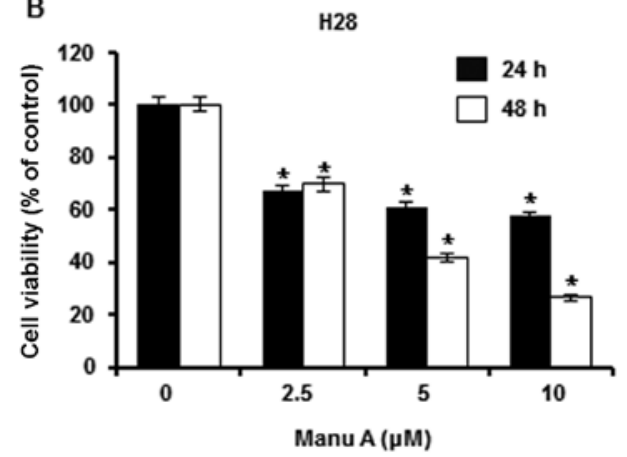

D $\stackrel{\circ}{\circ} 60, \quad H 28$

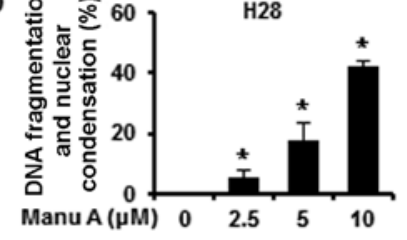

F

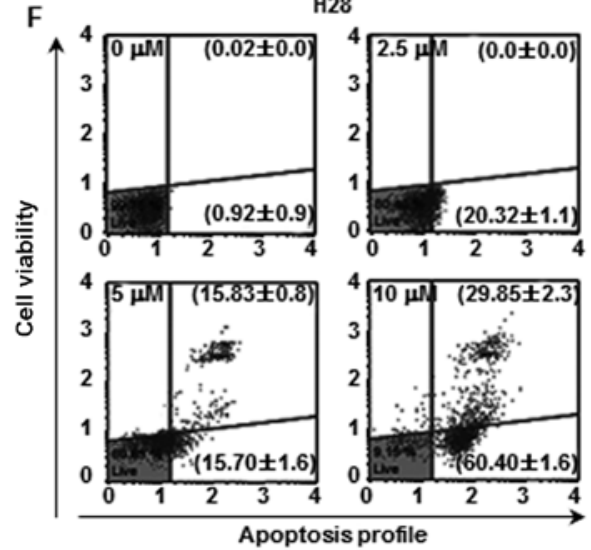

Figure 1. Effect of Manu A on the viability of malignant pleural mesothelioma (MPM). MSTO-211H (A) and H28 (B) cells were treated with $2.5,5$ and $10 \mu \mathrm{M}$ Manu A for 24 and $48 \mathrm{~h}$. The cell viability was monitored by MTS assay kits. DNA fragmentation and nuclear condensation were quantified using DAPI staining. Plots of DNA fragmentation and chromatin condensation (DAPI staining) were obtained for Manu A ( $2.5,5$ and $10 \mu \mathrm{M})$ after $48 \mathrm{~h}$ of incubation in the MSTO-211H (C) and H28 (D) cells. Data represent the mean percentage levels \pm SD (n=3). MSTO-211H (E) and H28 (F) cells were exposed to 0-10 $\mu \mathrm{M}$ Manu A for 48 h, stained with Annexin V/7-AAD, and then analyzed by Muse cell analyzer. The data are shown as the number of early apoptotic (bottom right quadrant), late apoptotic (upper right quadrant) and necrotic (upper left quadrant) cells after Manu A treatment and then normalized to the corresponding control cells. Values are mean $\pm \mathrm{SE}$ of triplicates from two independent experiments.

supernatant collection. Protein samples were separated by 10 or $15 \%$ SDS-polyacrylamide gel electrophoresis and transferred to polyvinylidene difluoride membranes (Millipore, Darmstadt, Germany) using standard procedures. The primary antibodies used were: Sp1, actin, poly (ADP-ribose) polymerase (PARP), cyclin D1, survivin, BID, Bcl-xL, Bax, CHOP, DR4 and DR5 (Santa Cruz Biotechonology, Santa Cruz, CA, USA) antibodies. The protein bands were detected using ECL Plus Western Blotting detection system (Santa Cruz Biotechnology).

Mitochondrial membrane potential (MMP) assay. To investigate the mitochondrial membrane permeability, the control and Manu A-treated (2.5, 5 and $10 \mu \mathrm{M})$ cells were harvested. After washing with phosphate-buffered saline (PBS), the cells were dissociated with trypsin. For detection of the depolarized mitochondria of cells undergoing apoptosis, MitoPotential working solution was added to the MPM cell culture and then reaction was carried out for $20 \mathrm{~min}$ in the dark. Muse 7-AAD was added to each well and samples were incubated in the dark at RT for $5 \mathrm{~min}$. The experiment was analyzed by Muse cell analyzer.

Multi-caspase activity. The process was carried out as instructed in the Muse Multi-Caspase kit (Merck Millipore). Each group, including negative and positive controls was harvested to quantitatively measure caspase activation and cell permeability. Cell samples in 1X caspase buffer with Muse Multi-Caspase reagent working solution were incubated at $37^{\circ} \mathrm{C}$ for $30 \mathrm{~min}$. Then, 7-AAD working solution was added to each triplicate sample and samples were analyzed by Muse Cell analyzer.

Statistical analysis. Data are presented as mean \pm SD of at least three independent experiments performed in triplicate. Data were analyzed for statistical significance using a one-way analysis of variance. A value of $\mathrm{p}<0.05$ was considered significant. 

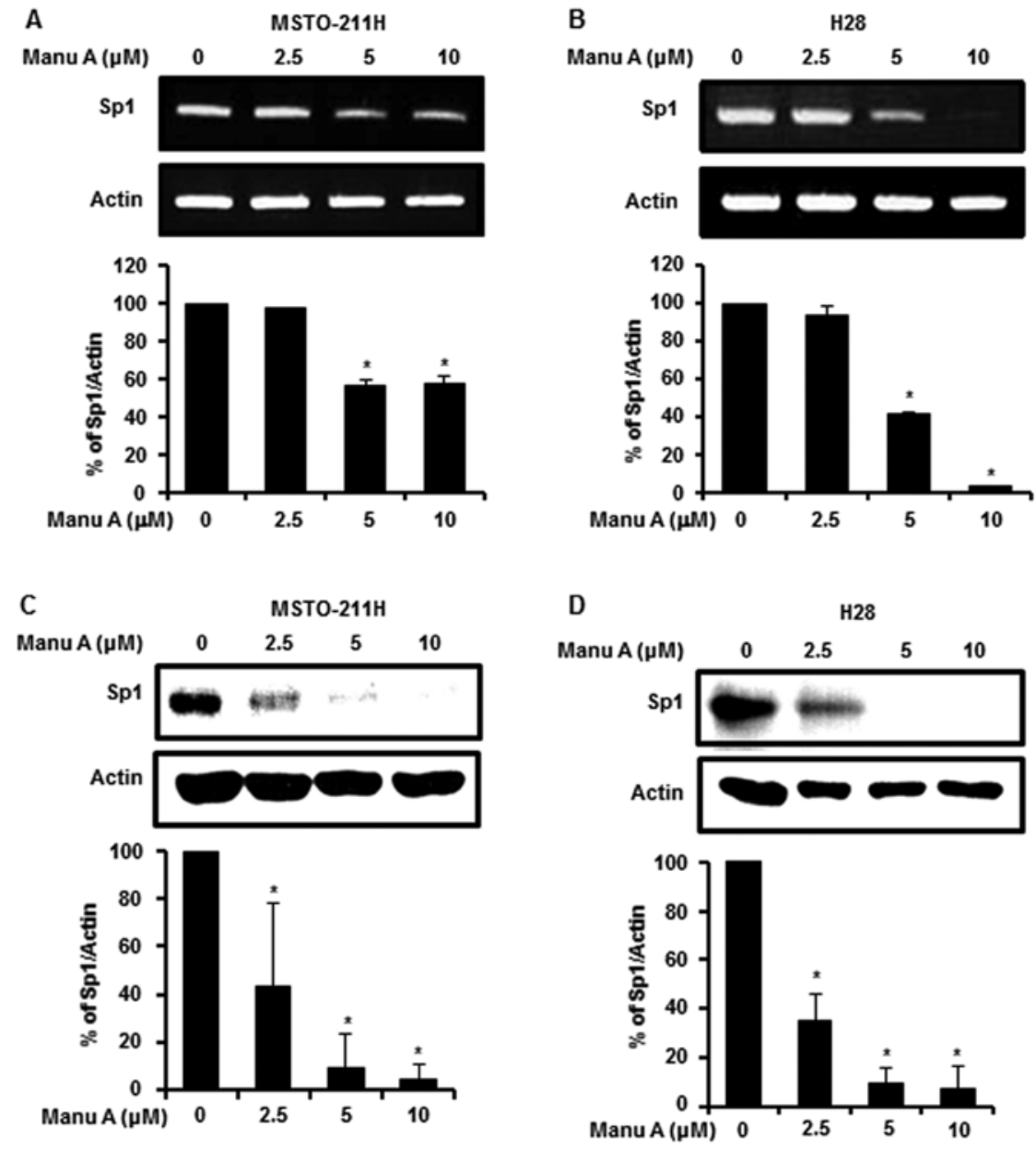

Figure 2. Manu A suppresses Sp1 protein via apoptosis in the MPM cells. (A) MSTO-211H and (B) H28 cells were treated with 2.5, 5 and $10 \mu \mathrm{M}$ Manu A for $48 \mathrm{~h}$. Afterwards, total RNAs were extracted and subjected to RT-PCR analysis. The graphs (A and B) indicate RNA expression levels of Sp1 normalized to actin. Whole cell extracts were prepared, separated on SDS-PAGE, and subjected to western blotting against Sp1 antibody (C and D). Actin was employed as a loading control. The graphs indicate the ratio of Sp1 to actin expression.

\section{Results}

The growth inhibitory effect of Manu A on malignant mesothelioma cells. To examine the cytotoxic effect of Manu A on the MSTO-211H (Fig. 1A) and H28 (Fig. 1B) MPM cell lines, MTS assay was carried out after treatment with Manu A at various concentrations $(2.5,5$ and $10 \mu \mathrm{M})$ for different times (24 and $48 \mathrm{~h}$ ). The $\mathrm{IC}_{50}$ of Manu A for cytotoxicity in the MSTO- $211 \mathrm{H}$ and $\mathrm{H} 28$ cells was 8.3 and $4.3 \mu \mathrm{M}$, respectively. Furthermore, to confirm the inhibitory effects of Manu A on cancer cell proliferation through apoptosis, we investigated morphological nuclear changes through DAPI staining. Manu A treatment effectively induced nuclear changes in the MPM cells in a dose-dependent manner. To quantify the cell death induced by Manu A, MPM cells were treated with Manu A at various concentrations $(2.5,5$ and $10 \mu \mathrm{M})$, and then we measured the number of apoptotic and necrotic cells by flow cytometry after staining with Annexin V and 7-AAD. The numbers of live cell were significantly reduced while cells undergoing apoptosis were increased in a concentration-dependent manner. In the MSTO-211H (Fig. 1E) and H28 cells (Fig. 1F), the total apoptotic cell population was increased from $11.15 \pm 0.9$ to $95.80 \pm 0.6 \%$ (MSTO-211H) and from $0.93 \pm 0.9$ to $90.25 \pm 1.2 \%$ (H28), respectively.
Manu A modulates Sp1 and Sp1-regulated proteins in the malignant mesothelioma cells. Sp1 plays an important role in oncogenesis, regulation of cell survival and death (13). To demonstrate the link between Sp1 and apoptosis, we investigated the expression level of Sp1 by RT-PCR and western blotting after treatment of the MPM cells with Manu A (2.5, 5 and $10 \mu \mathrm{M})$ for $48 \mathrm{~h}$. Sp1 mRNA expression levels in the MSTO-211H (Fig. 2A) and H28 (Fig. 2B) cells were reduced by Manu A in a dose-dependent manner. Consistent with mRNA levels, the Sp1 protein levels in the MSTO-211H and $\mathrm{H} 28$ cells were decreased in a dose-dependent manner (Fig. 2C and D). Sp1 is a transcription factor that modulates cell cycle regulation, anti-proliferative, and apoptosis cell death by regulating the promoter of target genes $(14,32)$. Moreover, Sp1 regulates expression of many proteins such as p21, p27, cyclin D1, Mcl-1 and survivin (33). Among a variety of genes involved, in this experiment, cyclin D1, Mcl-1 and survivin were investigated. After treatment of the cells with Manu A for $48 \mathrm{~h}, \mathrm{Sp1}$ target proteins in the MSTO-211H (Fig. 3A) and H28 cells (Fig. 3B) were downregulated.

Manu A has an effect on mitochondrial membrane permeability. There are two pathways which execute cell apoptosis; that is, the extrinsic pathway through activation of cell death 

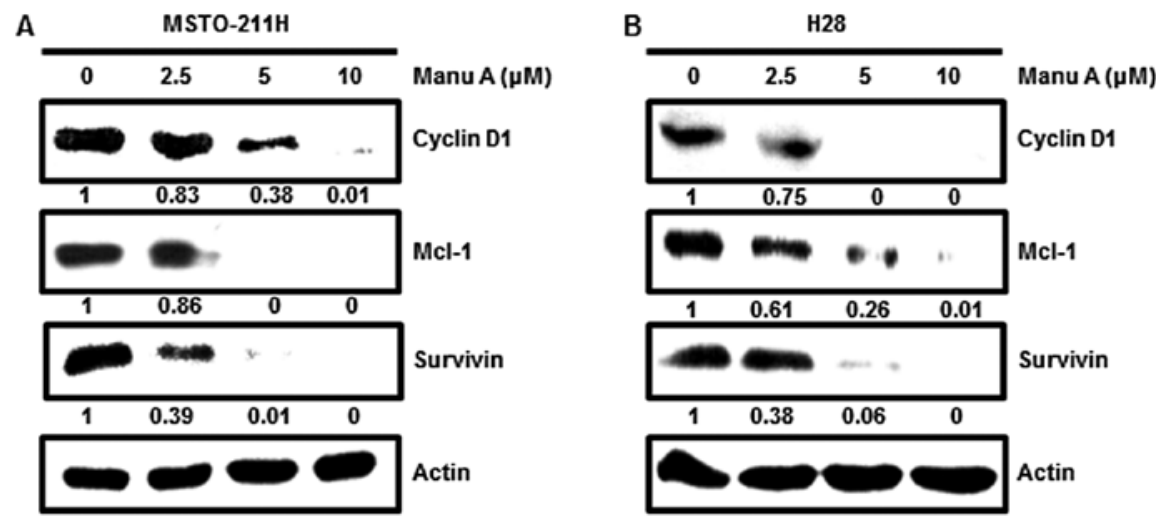

Figure 3. Effect of Manu A on Sp1-regulated proteins. (A) MSTO-211H and (B) H28 cells were treated with 2.5, 5 and $10 \mu \mathrm{M}$ Manu A for $48 \mathrm{~h}$, and whole cell extracts were prepared, separated on SDS-PAGE, and subjected to Western blotting using cyclin D1, Mcl-1 and survivin antibodies. Actin was used as a loading control. Representative results from three independent experiments are shown.
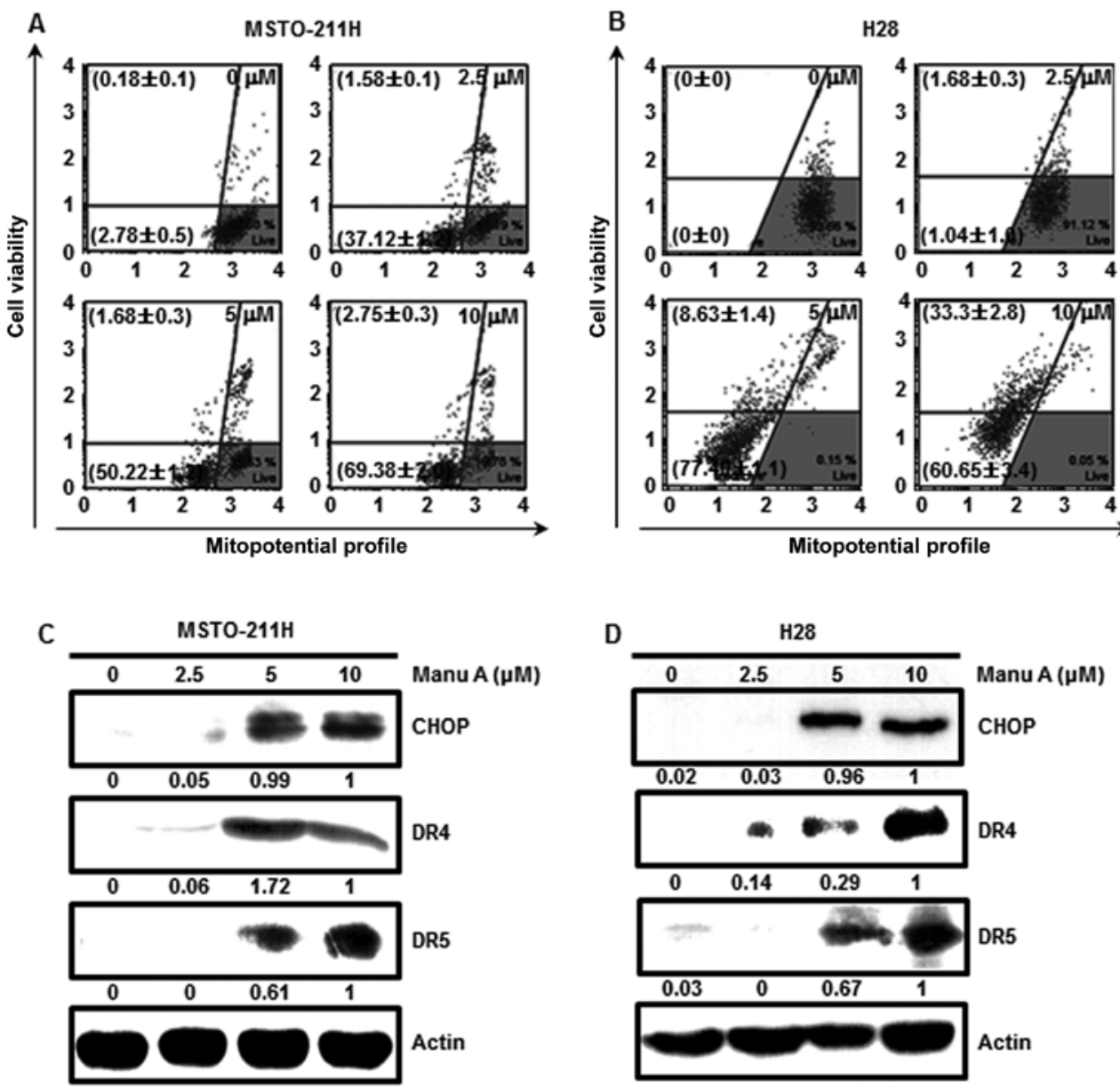

Figure 4. Effect of Manu A on mitochondrial membrane potential and Western blot analysis of apoptosis regulatory proteins in the MPM cells. MSTO-211H (A) and $\mathrm{H} 28$ (B) cells treated with Manu A $(2.5,5$ and $10 \mu \mathrm{M})$ were further cultured for $48 \mathrm{~h}$. To investigate the mitochondrial membrane permeability, these cells were incubated with $95 \mu \mathrm{l}$ of Muse MitoPotential working solution diluted with 1X assay buffer for $20 \mathrm{~min}$ in the dark. Then, $5 \mu 1$ of Muse 7-AAD was added and the samples were incubated at RT for $5 \mathrm{~min}$. Depolarization profiles of the mitochondrial membrane are shown in A and B. The data represent the mean percentage levels $\pm \mathrm{SD}(\mathrm{n}=3)$ for three independent experiments. The expression levels of CHOP and death receptor proteins (DR4 and DR5) were analyzed by western blotting in MSTO-211H (C) and H28 (D) cells. Actin was used as the loading control.

receptors and the intrinsic pathway through mitochondrial damage $(34,35)$. To confirm whether the mitochondrial pathway is activated by Manu A, we measured the degree of mitochondrial membrane potential. This was measured by staining with 5,5',6,6'-tetrachloro-1,1',3,3'-tetraethylbenzimid- azolylcarbocyanine iodide reagent in the MPM cells. As a result, MMP was significantly decreased in a concentrationdependent manner. Total depolarized MSTO-211H cell populations were $38.7 \pm 1.3,51.9 \pm 1.2$ and $72.1 \pm 1.7 \%$ and those of $\mathrm{H} 28$ (Fig. 4B) were $2.73 \pm 1.2,86.0 \pm 0.5$ and $93.9 \pm 0.9 \%$ at 
A

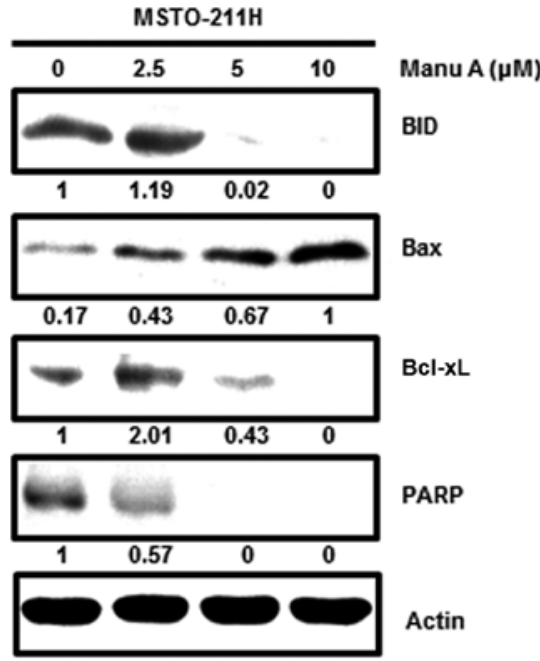

B

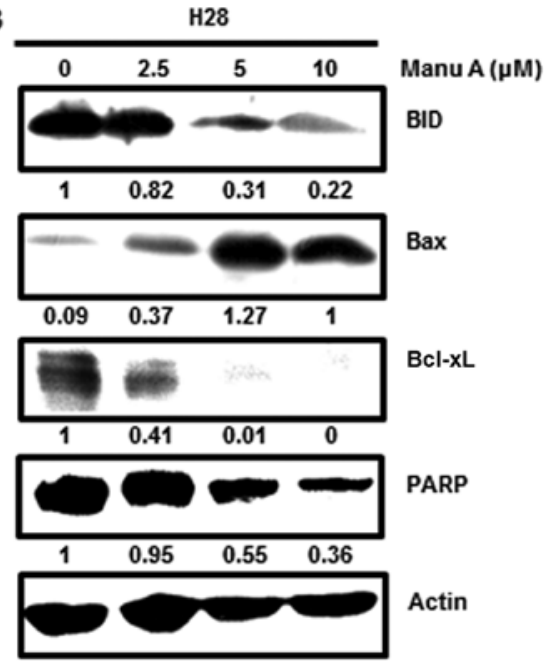

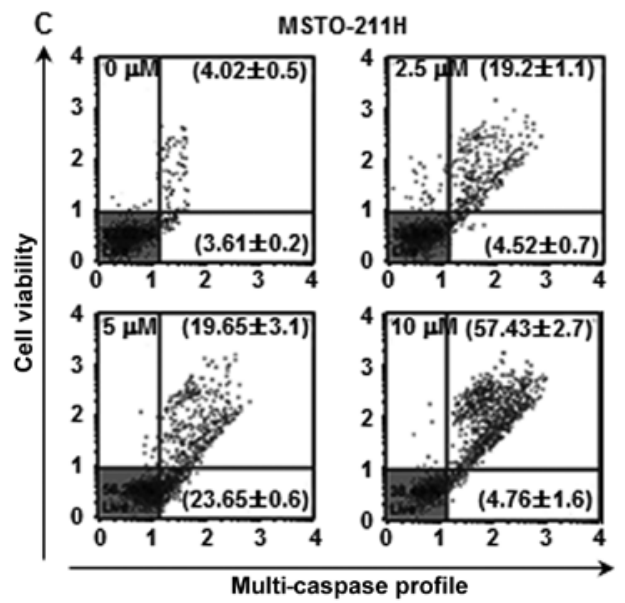

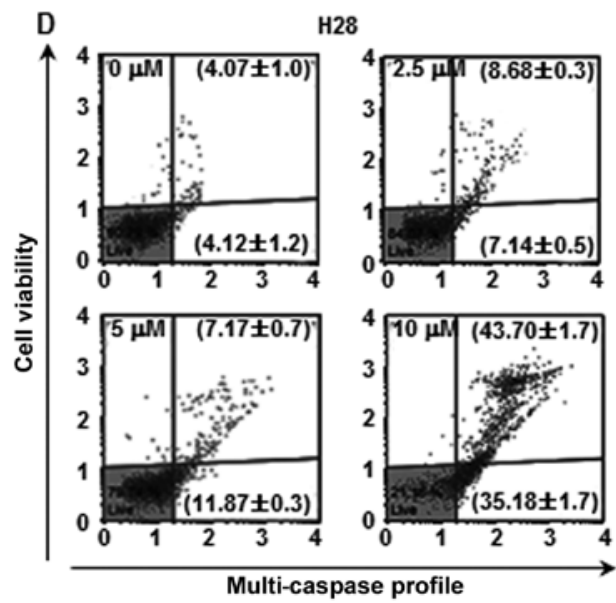

Figure 5. Effect of Manu A on the expression of anti-apoptotic and pro-apototic protein. (A) MSTO-211H and (B) H28 cells were treated with Manu A (2.5, 5 and $10 \mu \mathrm{M})$ for $48 \mathrm{~h}$, and then whole cell lysates were determined by western blot analysis with BID, Bax, Bcl-xL and PARP antibodies. Actin was used as an internal control to show equal loading of protein. The results shown are representative of three independent experiments. (C and D) Each quadrant indicates caspase-positive, caspase-positive/dead and dead cells in a counter-clockwise rotation. These results are representative of three independent experiments. Data represent the mean percentage levels $\pm \mathrm{SD}(\mathrm{n}=3)$.

increasing doses, respectively. To confirm whether Manu A could kill cells by inducing mitochondrial damage, we treated MPM cells with Manu A $(2.5,5$ and $10 \mu \mathrm{M})$ for $48 \mathrm{~h}$ and then carried out western blot analysis. CHOP is increased by ER stress and the cell death receptors such as DRs (DR4 and DR5) are upregulated by cell stress $(36,37)$. Based on our results, CHOP, DR4 and DR5 were increased in a concentrationdependent manner (Fig. 4C and D).

Manu A regulates the expression of apoptosis-related proteins in the MSTO-211Hand H28cells. Treatment of the MSTO-211H and H28 cells with Manu A regulated the expression levels of apoptosis-related proteins. To clarify the association between Manu A and Sp1-mediated apoptosis, we performed western blot analysis. When MPM cells were treated with Manu A, Bax expression was increased in a concentration-dependent manner, while the expression of Bcl-xL, an apoptosis inhibitory protein, was reduced in a concentration-dependent manner (Fig. 5A and B). PARP that interferes with the apoptosis of cancer cells is decreased (38). In this experiment, PARP was decreased in both the MPM cell lines following treatment with
Manu A (Fig. 5A and B). When cells are exposed to internal and external stimuli, apoptotic signals are transmitted to induce activation of caspase- 8 and -9 . Then, procaspase- 3 is cleaved into caspase-3, and inactivates PARP finally inducing apoptosis (35). To examine whether Manu A-mediated apoptosis could be associated with caspases, the caspase activity was measured using a multi-caspase kit. Total multi-caspase activities in the MSTO-211H cells (Fig. 5C) were 23.7 \pm 1.3 , 43.3 \pm 3.4 and $62.2 \pm 1.1 \%$, and those in the H28 cells (Fig. 5D) were $15.8 \pm 0.7,19.0 \pm 0.5$ and $78.9 \pm 0.5 \%$ at increasing doses. From the above results, we confirmed that Manu A regulated the expression of apoptosis-related proteins in the MPM cells.

\section{Discussion}

Due to environmental pollution and unhealthy dietary habits, the incidence of cancer is increasing. For the treatment of these diseases, various therapeutic anticancer agents have been developed (39). Among various cancers, MPM is a rare, but aggressive form of cancer with poor prognosis $(2,7)$. It is closely associated with exposure to asbestos, radiation or 
simian virus $40(1,2)$. Targeting the apoptotic pathway of MPM to effectively halt tumor progression would be ideal to develop effective treatments for MPM. Our results showed that Manu A is a potential chemotherapeutic agent for MPM through the mitochondrial pathway and that $\mathrm{Spl}$ is a potential therapeutic target of Manu A.

It has been reported that $\mathrm{Sp} 1$ is associated with tumor growth and is overexpressed in many types of human tumors (15). A number of studies have reported that $\mathrm{Sp1}$ is highly expressed in a variety of human tumors and that the use of natural compounds may be used to inhibit Sp1 expression in cancer (33). The effectiveness of anticancer agents is closely dependent on apoptosis induction. Therefore, biochemical mechanisms of apoptosis for cancer treatment should be well understood (40). The precise apoptotic mechanisms of Manu A in MPM cells remain undetermined, thus we investigated the apoptotic effects and pathway in the inhibition of Sp1 protein expression by Manu A in the MSTO-211H and H28 cells.

First, as shown in the MTS assay, the survival rate of the MPM cell lines was significantly reduced in a concentrationdependent manner by Manu A. In order to investigate whether the cell death would be associated with Manu A, DAPI and Annexin V/7-AAD staining were performed. Data showed that the numbers of MPM cells were significantly reduced in a dose-dependent manner while the number of apoptotic cells increased.

Our results showed that Manu A inhibited Sp1 expression at both the protein and mRNA levels. Since Manu A modulates the expression of the Sp1 protein, it was also important to determine the response of key candidates related to apoptosis in its downstream signaling pathway. Manu A suppressed Sp1 downstream target genes, including cyclin D1, Mcl-1 and survivin in the MSTO-211H and H28 cells as detected by western blot analyses.

In the process of cell death induction in cancer cells, both apoptosis-promoting protein and apoptosis inhibitory proteins play important roles (31). They are located inside and outside of the mitochondria and are increased or decreased by cell death factors activated by apoptosis signaling factors $(41,42)$. We investigated the mitochondrial membrane permeability during apoptosis in the MPM cells. Based on the results, Manu A modulated cell stress and mitochondrial integrity of the MPM cells. Moreover, we determined the response on core elements related to apoptosis in the mitochondrial signaling pathway. Therefore, the effect of Manu A on CHOP, DR4 and DR5 in both cell lines was examined.

To confirm whether Manu A could modulate apoptosisrelated proteins in the MPM cells, western blot analyses were carried out. As a result, it was confirmed that BID, Bcl-xL and PARP were reduced. In addition, expression of Bax can be considered to induce the release of cytochrome $c$ by abolishing MMP $(35,40)$. A downstream protein of apoptosis active caspase- 3 was increased in a concentration-dependent manner and PARP protein was decreased in a dose-dependent manner. These in vitro results suggest that Manu A modulates apoptosis-related proteins in MPM cells.

Based on the results above, Manu A has therapeutic and chemopreventive benefits and $\mathrm{Sp} 1$ is a therapeutic target in MPM cells. We conclude that Manu A downregulated Sp1 protein levels, which in turn induced cell apoptosis of MPM cells through both the intrinsic and the extrinsic pathways. Therefore, Manu A is promising as an anticancer agent.

\section{Acknowledgements}

This research was supported by the Basic Science Research Program through the National Research Foundation Korea (NRF) Funded by the Ministry of Education, Science and Technology (2014R1A1A2053500) and the Next-Generation BioGreen 21 Program (PJ01116401) from Rural Development Administration, Republic of Korea.

\section{References}

1. Carbone M, Ly BH, Dodson RF, Pagano I, Morris PT, Dogan UA, Gazdar AF, Pass HI and Yang H: Malignant mesothelioma: Facts, myths, and hypotheses. J Cell Physiol 227: 44-58, 2012.

2. Pass HI, Vogelzang N, Hahn S and Carbone M: Malignant pleural mesothelioma. Curr Probl Cancer 28: 93-174, 2004.

3. Attanoos RL and Gibbs AR: Pathology of malignant mesothelioma. Histopathology 30: 403-418, 1997.

4. Linton A, Cheng YY, Griggs K, Kirschner MB, Gattani S, Srikaran S, Chuan-Hao Kao S, McCaughan BC, Klebe S, van Zandwijk N, et al: An RNAi-based screen reveals PLK1, CDK1 and NDC80 as potential therapeutic targets in malignant pleural mesothelioma. Br J Cancer 110: 510-519, 2014.

5. Spugnini EP, Bosari S, Citro G, Lorenzon I, Cognetti $F$ and Baldi A: Human malignant mesothelioma: Molecular mechanisms of pathogenesis and progression. Int $\mathrm{J}$ Biochem Cell Biol 38: 2000-2004, 2006.

6. Tatsuta T, Hosono M, Takahashi K, Omoto T, Kariya Y, Sugawara S, Hakomori S and Nitta K: Sialic acid-binding lectin (leczyme) induces apoptosis to malignant mesothelioma and exerts synergistic antitumor effects with TRAIL. Int J Oncol 44: 377-384, 2014.

7. Sahin AA, Cöplü L, Selçuk ZT, Eryilmaz M, Emri S, Akhan O and Bariş YI: Malignant pleural mesothelioma caused by environmental exposure to asbestos or erionite in rural Turkey: CT findings in 84 patients. AJR Am J Roentgenol 161: 533-537, 1993.

8. Carbone M, Kratzke RA and Testa JR: The pathogenesis of mesothelioma. Semin Oncol 29: 2-17, 2002.

9. Zucali PA, Ceresoli GL, De Vincenzo F, Simonelli M, Lorenzi E, Gianoncelli L and Santoro A: Advances in the biology of malignant pleural mesothelioma. Cancer Treat Rev 37: 543-558, 2011.

10. Cedrés S, Montero MA, Zamora E, Martínez A, Martínez P, Fariñas L, Navarro A, Torrejon D, Gabaldon A, Ramon Y Cajal S, et al: Expression of Wilms' tumor gene (WT1) is associated with survival in malignant pleural mesothelioma. Clin Transl Oncol 16: 776-782, 2014.

11. Martinis UJ and Radovic VR: Pleural mesothelioma in patient with pulmonary tuberculosis: Report of a case. Dis Chest 47: 568-570, 1965.

12. Tanaka I, Osada H, Fujii M, Fukatsu A, Hida T, Horio Y, Kondo Y, Sato A, Hasegawa Y, Tsujimura T, et al: LIM-domain protein AJUBA suppresses malignant mesothelioma cell proliferation via Hippo signaling cascade. Oncogene 34: 73-83, 2015.

13. Safe $\mathrm{S}$ and Abdelrahim M: Sp transcription factor family and its role in cancer. Eur J Cancer 41: 2438-2448, 2005.

14. Aslam F, Palumbo L, Augenlicht LH and Velcich A: The Sp family of transcription factors in the regulation of the human and mouse MUC2 gene promoters. Cancer Res 61: 570-576, 2001.

15. Black AR, Black JD and Azizkhan-Clifford J: Sp1 and krüppel-like factor family of transcription factors in cell growth regulation and cancer. J Cell Physiol 188: 143-160, 2001.

16. Tsuda M, Okamoto K, Muguruma N, Sannomiya K, Nakagawa T, Miyamoto H, Kitamura S, Goji T, Kimura T, Okahisa T, et al: Suppressive effect of RAS inhibitor manumycin A on aberrant crypt foci formation in the azoxymethane-induced rat colorectal carcinogenesis model. J Gastroenterol Hepatol 28: 1616-1623, 2013.

17. Hara M, Akasaka K, Akinaga S, Okabe M, Nakano H, Gomez R, Wood D, Uh M and Tamanoi F: Identification of Ras farnesyltransferase inhibitors by microbial screening. Proc Natl Acad Sci USA 90: 2281-2285, 1993. 
18. Singha PK, Pandeswara S, Venkatachalam MA and Saikumar P: Manumycin A inhibits triple-negative breast cancer growth through LC3-mediated cytoplasmic vacuolation death. Cell Death Dis 4: e457, 2013.

19. Kainuma O, Asano T, Hasegawa M, Kenmochi T, Nakagohri T, Tokoro $\mathrm{Y}$ and Isono $\mathrm{K}$ : Inhibition of growth and invasive activity of human pancreatic cancer cells by a farnesyltransferase inhibitor, manumycin. Pancreas 15: 379-383, 1997.

20. Yeung SC, Xu G,Pan J, Christgen M and Bamiagis A: Manumycin enhances the cytotoxic effect of paclitaxel on anaplastic thyroid carcinoma cells. Cancer Res 60: 650-656, 2000.

21. Pan J, Xu G and Yeung SC: Cytochrome c release is upstream to activation of caspase-9, caspase- 8 , and caspase- 3 in the enhanced apoptosis of anaplastic thyroid cancer cells induced by manumycin and paclitaxel. J Clin Endocrinol Metab 86: 4731-4740, 2001

22. Di Paolo A, Danesi R, Nardini D, Bocci G, Innocenti F, Fogli S, Barachini S, Marchetti A, Bevilacqua G and Del Tacca M: Manumycin inhibits ras signal transduction pathway and induces apoptosis in COLO320-DM human colon tumour cells. Br J Cancer 82: 905-912, 2000.

23. Zhou JM, Zhu XF, Pan QC, Liao DF, Li ZM and Liu ZC: Manumycin induces apoptosis in human hepatocellular carcinoma HepG2 cells. Int J Mol Med 12: 955-959, 2003.

24. Wang W and Macaulay RJ: Apoptosis of medulloblastoma cells in vitro follows inhibition of farnesylation using manumycin A. Int J Cancer 82: 430-434, 1999.

25. Selleri C, Maciejewski JP, Montuori N, Ricci P, Visconte V, Serio B, Luciano L and Rotoli B: Involvement of nitric oxide in farnesyltransferase inhibitor-mediated apoptosis in chronic myeloid leukemia cells. Blood 102: 1490-1498, 2003.

26. She M, Pan I, Sun L and Yeung SC: Enhancement of manumycin A-induced apoptosis by methoxyamine in myeloid leukemia cells. Leukemia 19: 595-602, 2005

27. Frassanito MA, Cusmai A, Piccoli C and Dammacco F: Manumycin inhibits farnesyltransferase and induces apoptosis of drug-resistant interleukin 6-producing myeloma cells. Br J Haematol 118: 157-165, 2002.

28. Sears KT, Daino H and Carey GB: Reactive oxygen species-dependent destruction of MEK and Akt in Manumycin stimulated death of lymphoid tumor and myeloma cell lines. Int J Cancer 122: 1496-1505, 2008.

29. Pathak S, Sharma C, Jayaram HN and Singh N: Apoptotic signaling induced by benzamide riboside: An in vitro study. Mol Cell Biochem 328: 67-73, 2009.
30. Reed JC: Apoptosis mechanisms: Implications for cancer drug discovery. Oncology (Williston Park) 18 (Suppl 10): 11-20, 2004.

31. Lowe SW and Lin AW: Apoptosis in cancer. Carcinogenesis 21: 485-495, 2000

32. Courey AJ and Tjian R: Analysis of Sp1 in vivo reveals multiple transcriptional domains, including a novel glutamine-rich activation motif. Cell 55: 887-898, 1988.

33. Cho JJ, Chae JI, Yoon G, Kim KH, Cho JH, Cho SS, Cho YS and Shim JH: Licochalcone A, a natural chalconoid isolated from Glycyrrhiza inflata root, induces apoptosis via $\mathrm{Sp1}$ and $\mathrm{Sp1}$ regulatory proteins in oral squamous cell carcinoma. Int J Oncol 45: 667-674, 2014.

34. Banjerdpongchai R, Wudtiwai B and Pompimon W: Stigmalactam from Orophea enterocarpa induces human cancer cell apoptosis via a mitochondrial pathway. Asian Pac J Cancer Prev 15: 10397-10400, 2014.

35. Lim SW, Loh HS, Ting KN, Bradshaw TD and Zeenathul NA: Antiproliferation and induction of caspase-8-dependent mitochondria-mediated apoptosis by $\beta$-tocotrienol in human lung and brain cancer cell lines. Biomed Pharmacother 68: 1105-1115, 2014.

36. Yang X, Du T, Wang X, Zhang Y, Hu W, Du X, Miao L and Han C: IDH1, a CHOP and C/EBP $\beta$-responsive gene under ER stress, sensitizes human melanoma cells to hypoxia-induced apoptosis. Cancer Lett 365: 201-210, 2015.

37. Ghosh AP, Klocke BJ, Ballestas ME and Roth KA: CHOP potentially co-operates with $\mathrm{FOXO} 3 \mathrm{a}$ in neuronal cells to regulate PUMA and BIM expression in response to ER stress. PLoS One 7: e39586, 2012.

38. Kharbanda S, Pandey P, Schofield L, Israels S, Roncinske R, Yoshida K, Bharti A, Yuan ZM, Saxena S, Weichselbaum R, et al: Role for Bcl-xL as an inhibitor of cytosolic cytochrome C accumulation in DNA damage-induced apoptosis. Proc Natl Acad Sci USA 94: 6939-6942, 1997.

39. Siegel R, Ma J, Zou Z and Jemal A: Cancer statistics, 2014. CA Cancer J Clin 64: 9-29, 2014.

40. Wong WW and Puthalakath $\mathrm{H}$ : Bcl-2 family proteins: The sentinels of the mitochondrial apoptosis pathway. IUBMB Life 60: 390-397, 2008.

41. Scatena R: Mitochondria and cancer: A growing role in apoptosis, cancer cell metabolism and dedifferentiation. Adv Exp Med Biol 942: 287-308, 2012.

42. Martinou JC and Youle RJ: Mitochondria in apoptosis: Bcl-2 family members and mitochondrial dynamics. Dev Cell 21: 92-101, 2011. 